\title{
Strengthening The Curriculum Of Information Systems Program
}

Shafaq Naheed Khan, University of Dubai, UAE

\begin{abstract}
Information Systems as a field of academic study has witnessed tremendous growth in scope and depth since its beginning in the 1960s. Diversified information systems job market and widespread use of technology in healthcare organizations indicate a growing demand for IT personnel in healthcare organizations. This paper attempts to present a model for designing curriculum for Healthcare Information Systems concentration for an IT undergraduate program. The design of this curriculum is based on the recommendations of the Accreditation Board for Engineering \& Technology (ABET) Computing Accreditation Commission (CAC). This model can be used by any higher educational institute that plans to redesign its IT curriculum to offer specializations. Lessons learnt indicate a need to get employers involved in the design process so that the knowledge and skill areas of the curriculum are responsive to the employer's requirements.
\end{abstract}

Keywords: curriculum; concentration; undergraduate program; information systems

\section{INTRODUCTION}

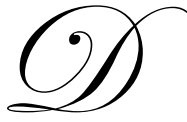

eveloping and revitalizing the Information Systems (IS) curricula is an evolutionary process because of the exponential development of technology (Hunt, 2004; Dodson \& Giorcelli, 2008). Bewer, Horriger \& Medonca (2006) also state that curriculum must be able to adapt constantly to the everchanging environment.

According to Noll and Wilkins (2002), IS jobs are becoming diversified and that generic IS curriculum will not meet all the needs for all IS jobs. According to them, the curricula could be developed consisting of separate and distinctive concentrations targeting the diverse job market requirements. Creating new tracks within the IS major can also play a role in increasing enrollments in IT/IS programs (Lenox, Woratschek \& Davis, 2008).

While considering the concentrations to be offered in an IS program, it is important to offer specialization fields that will address the local employment needs. With rapid growth of Information Technology in the field of healthcare, there is a need growing worldwide for IT personnel specialized in healthcare. Health information technology has the potential to upgrade the health care system with information delivery where it is needed and refocusing health care around the consumer (Thompson \& Brailer, 2004). As observed by Lang (2003), healthcare workers with IT knowledge base are in great demand. At the regional level, healthcare has been a priority for the UAE government, with an emphasis on positioning the UAE as a major healthcare provider (Grant Thornton's International Business Report, 2010) and this unprecedented growth is expected to continue its pace in future (Pharmaceutical Market Research, 2011). This growth has resulted in an increasing demand for healthcare professionals in UAE (newzglobe.com, 2011). According to a report by Mourshed,Hediger \& Lambert (2006), Gulf Cooperation Council (GCC) is unable to produce sufficient number of staff to provide health care for its population. As a result, dependency on the foreign workers is too high. At the same time, there is a growing rate of unemployment among nationals in GCC countries (Mourshed et al., 2006). UAE government is responding to this concern by rigorously implementing Emiratization - an initiative by the government of UAE to provide jobs to local Emiratis. Emiratization has resulted in need for well-educated Emirati professionals with diverse skills and knowledge. 


\section{Program Redesign Drivers}

Literarture review shows that Curriculum re-design is not only essential in this ever-changing field of information systems but also a necessity for educational institutions to maintain their competitive advantage.

UAE government's support for healthcare, positive healthcare prospects in the GCC region and an increase in investment in the healthcare sector indicate high employment potential for the work force specialized in this sector. UAE government's Emiratizations initiative signifies a strong need in the UAE employment market for graduates with the specialization in Health Care Information Systems. It thus becomes the responsibility of higher educational institutions in the region to offer programs to meet the market demands. College of Information Technology is the institution in the region becoming part of the solution by redesign its program to offer IT undergraduate degree with specialization in healthcare information systems.

How can a university or a college design undergraduate IS concentration program curriculum that is aligned with the university's mission and that meets the quality standards?

The purpose of this paper is to present a model (shown in Figure 1) that describes the design of curriculum for a concentration in IT undergraduate program. A case study of Health Care Information Systems (HCIS) concentration for the Computer Information Systems undergraduate program developed at College of Information Technology is used in presenting this model. Model consists of three phases as below:

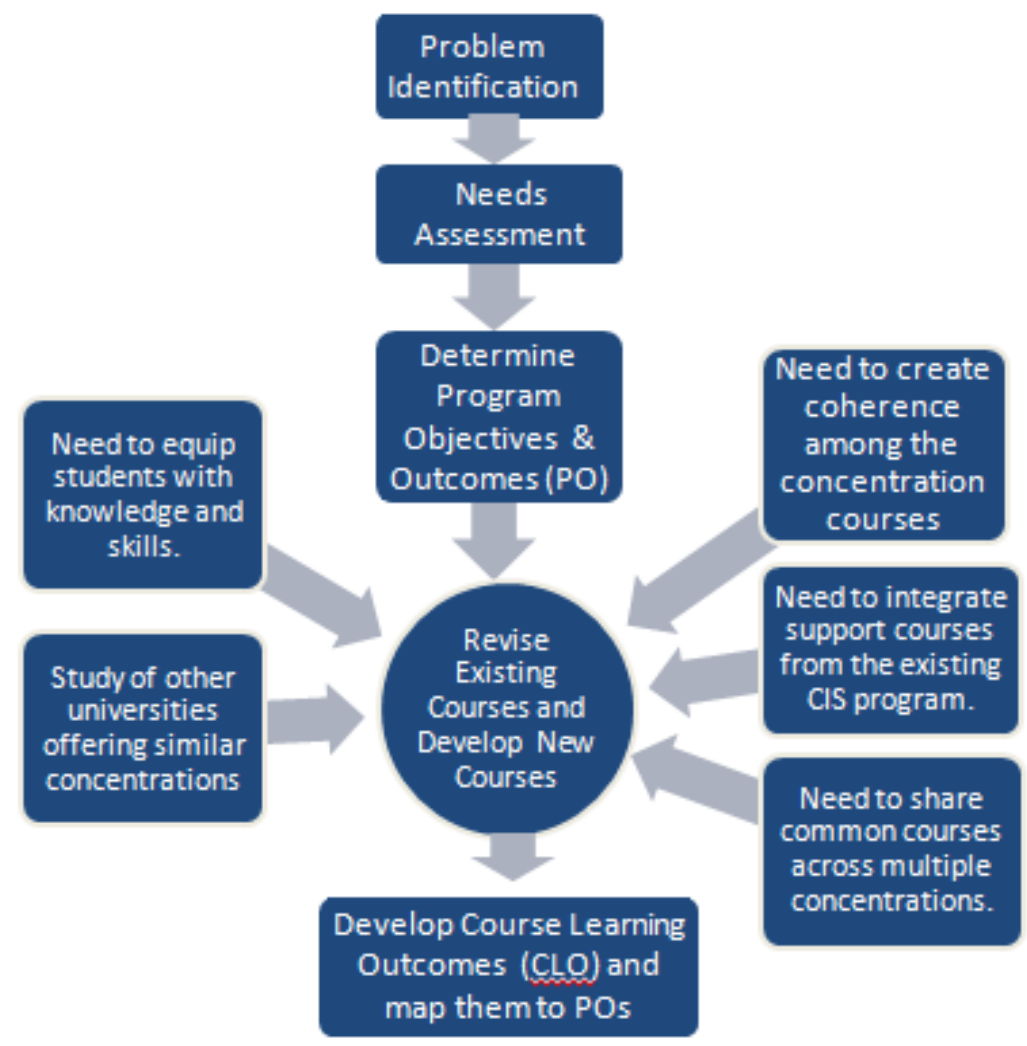

Figure 1: Curriculum Development Model

Phase A of the curriculum design deals with assessing the feasibility of offering this concentration. 
Phase B of the model encompasses the curriculum design of the HCIS concentration. It deals with developing the concentration objectives and outcomes that are in alignment with university's mission of preparing high caliber graduates of lifelong learning and serving the educational and professional needs of all stakeholders. These objectives and outcomes are mapped to the current CIS program objectives \& outcomes.

Phase $\mathrm{C}$ of this model deals with designing the concentration courses in the curriculum. Several criteria like ABET requirements, courses offered at the college currently, local market needs, coherence, and sharing of concentrations courses were the factors that helped in deciding the courses with their objectives \& outcomes. These course objectives and outcomes became the basis in developing the course content and their assessment tools.

Conclusions and recommendations are given at the end of the paper.

\section{BACKGROUND}

The College of Information Technology (CIT) offers BSc. in Computer Information Systems (CIS) program since 2001. CIS program is accredited internationally by the Computing Accreditation Commission (CAC) of the Accreditation Board for Engineering and Technology (ABET) in USA.

Plans to redesign the CIS program resulted in a proposal to offer the the same program with six different concentrations. Health Care Information Systems (HCIS) was one of the proposed concentrations to be added to the curriculum. Other proposed concentrations included Enterprise Information Systems, Information Systems Security, Electronic \& Mobile commerce, Network Administration \& Support and Database Systems.

\section{PHASE A: FEASIBILITY STUDY}

With a view to assess the feasibility of offering a program, following questions should be considered:

- Is there a requirement for this concentration at the regional and the national level?

- Is this concentration going to serve the purpose of the beneficiary institution?

- If this program would invite sufficient numbers of prospective students?

- Is the institution ready with the faculty, library \& laboratory facilities and other support services needed for implementation of the concentration?

Last two questions are beyond the scope of this paper and hence not discussed. Feasibility study of offering HCIS concentration at CIT is as follows:

\section{Competing Institutions}

No higher educational institution in Dubai is currently offering HCIS concentration with a focus on information technology. Therefore, there is no perceptible threat from the competitors.

\section{Prospective Employers}

There are around 36 hospitals in UAE. Dubai Chamber of Commerce has established Dubai Healthcare City (DHCC), an ongoing project worth $\$ 3$ billion, as well as the $\$ 400$ million Dubai Biotechnology and Research Park (DuBiotech) (Gulf News, 2008). DHCC has the distinction to be the world's first healthcare free zone. It is one of the numerous specialized 'City-within-a-City' in Dubai targeting phenomenal growth in healthcare and pharmaceutical industries. The project comprises of a collection of medical teaching institutions, private hospitals and clinics, pharmaceutical research centers, their offices, spas and rehabilitation centers. Overall, there are 17 hospitals planned for DHCC. Currently these are partially functional and expected to be operational in near future.

A recent estimate by Mckinsey and Company (newzglobe.com, 2011), points to a doubling of demand for hospital beds in the GCC region by 2025. As per the report, top international healthcare providing companies are set to enter the market with plans for fresh hospitals afoot. Huge investment is going on in the healthcare sector across 
the GCC, mainly in Abu Dhabi and Saudi Arabia, paving the way for the opening of around 250 to 400 new hospitals across the Gulf region in next 5 to 10 years (Singh, 2011).

The initiative of establishing DHCC and DuBiotech aligned with positive healthcare prospects in the Gulf would trigger a pent-up demand for healthcare professionals in UAE and across the region.

\section{Areas Of Strength}

College of Information Technology has affiliation with the Dubai Chamber (DC-formerly known as Dubai Chamber of Commerce and Industry). CIT's close contact with the IT/business community through the DC has meant that its programs are respected by the IT/business community at large and thus will promote the students to enroll themselves for HCIS concentration program.

\section{PHASE B: DESIGNING THE FRAMEWORK}

\section{Defining The Program Objectives And Outcomes}

Several available curriculum models provide guidelines for adoption and further shaping the curriculum for undergraduate programs. Recent public draft of IS 2009 and its predecessors IT 2008, OEIS (Organizational EndUser Information Systems) and MTC (Managerial, Technical \& Communication) models are there to name a few. The IS 2002 curriculum model is closely linked to ABET accreditation. Use of IS 2002 curriculum model assists in ABET accreditation (Landry et al., 2010). Curriculum models like ACM/IEEE - IT Curriculum Model 2008 also encourages ABET-CAC accreditation for IT programs that follow their curriculum. Hence, accreditor's guidelines are equally important and can be used for developing and analyzing the curricula.

ABET describes Program Educational Objectives as "broad statements that describe the career and professional accomplishments that the program is preparing graduates to achieve."(ABET)

ABET describes Program Outcomes as "narrower statements that describe what students are expected to know and be able to do by the time of graduation. These relate to the skills, knowledge, and behaviors that students acquire in their matriculation through the program" (ABET). Program Outcomes (PO) provide focus for institutional strategies for student learning and emerge from objectives.

ABET requires that programs seeking their accreditations must meet the nine criteria. Two of these nine criteria, related to the program objectives and outcomes are:

- $\quad$ Criterion 2. The program has documented, measurable educational objectives that are based on the needs of the program's constituencies.

- Criterion 3. The program has documented, measurable outcomes that are based on the needs of the program's constituencies. (ABET) graduation:

Specifically, the guidelines emphasize that the program enables students to achieve, by the time of

- $\quad$ "An ability to apply knowledge of computing and mathematics appropriate to the discipline

- An ability to analyze a problem, and identify and define the computing requirements appropriate to its solution

- An ability to design, implement, and evaluate a computer-based system, process, component, or program to meet desired needs

- $\quad$ An ability to function effectively on teams to accomplish a common goal

- An understanding of professional, ethical, legal, security and social issues and responsibilities

- $\quad$ An ability to communicate effectively with a range of audiences

- An ability to analyze the local and global impact of computing on individuals, organizations, and society 
- $\quad$ Recognition of the need for and an ability to engage in continuing professional development

- $\quad$ An ability to use current techniques, skills, and tools necessary for computing practice.

- An understanding of processes that support the delivery and management of information systems within a specific application environment. [IS]" (ABET)

\section{Accreditation Requirements Incorporated At CIT}

The educational outcomes assessment system at CIT performs the following processes:

- Develop Program Objectives for the program.

- $\quad$ Develop Program Outcomes.

- $\quad$ Identify outcome measures for each PO.

- $\quad$ Specify/Design instruments to measure actual achievement of the expected outcome.

The objectives and outcomes of the CIS program strongly conform to the university mission. Concentration in HCIS comes under the umbrella of the CIT's CIS program. An important design aspect of the HCIS concentration was to design the objectives and outcomes of the HCIS concentration that would relate to the objectives and outcomes of the CIS program and are in agreement with the ABET criteria. Objectives and outcomes of the BSc. CIS with concentration in HCIS are thus defined as:

\section{Program Objectives (With Concentration In HCIS)}

The CIS program with concentration in HCIS is designed to prepare graduates who are able to:

1. Demonstrate knowledge of concepts and practices of healthcare systems and the processes required to support health service delivery.

2. Understand and analyze the important issues with regard to the social impact of advanced and emerging computer information technologies

3. Apply a variety of techniques, software tools, and applications to enhance the effectiveness and efficiency of health care organizations.

4. Formulate questions and critically investigate and solve business-related computing \& information systems problems

5. Be engaged in ethical issues in information systems, particularly questions of social responsibility and professional decision-making

6. Build and lead team of professionals to tackle challenging, Computing \& Information Systems Projects

7. Communicate effectively and professionally with technical and non-technical professionals.

CIS program objectives 2,4,5,6 and 7 are common for all six IT concentrations and hence generic to information systems while CIS program objectives 1 and 3 are specific to the HCIS concentration.

\section{Program Outcomes (With Concentration In HCIS)} ability to:

Upon graduation, each CIS graduate with concentration in HCIS will possess the knowledge, skills, and

1. Apply knowledge of computing, information systems, and mathematics.

2. Analyze a healthcare IS-related problem, identify, and define the computing and information systems requirements appropriate to its solution.

3. Design, implement, and evaluate a computer-based system, process, component, or program to meet desired needs.

4. Function effectively in teams to create a project plan to accomplish a common goal.

5. Understand professional, ethical, and social responsibilities.

6. Communicate effectively with a range of audiences. 
7. Analyze the impact of computing on individuals, organizations, and society, including ethical, legal, security, and global policy issues.

8. Apply current techniques, skills, and tools to enhance the operational and managerial aspects of healthcare organizations.

9. Understand the organizational, administrative, managerial, and regulatory processes that support the delivery and management of evolving health systems.

CIS program outcome 1, 3,4,5,6 and 7 are common for all the six IT concentrations and hence generic to information systems while program outcome 2, 8 , and 9 are specific to the HCIS concentration.

The mapping between the HCIS concentration outcomes and the corresponding HCIS concentration objectives are highlighted in Table 1.

Table 1: Mapping Of HCIS Concentration Objectives To HCIS Outcomes

\begin{tabular}{|c|c|c|c|c|c|c|c|}
\hline \multirow[t]{2}{*}{ HCIS Concentration Outcomes } & \multicolumn{7}{|c|}{$\begin{array}{l}\text { HCIS Concentration } \\
\text { Objectives }\end{array}$} \\
\hline & 1 & 2 & 3 & 4 & 5 & 6 & 7 \\
\hline Apply knowledge of computing, information systems, and mathematics. & & & $\mathrm{X}$ & $\mathrm{X}$ & & & \\
\hline $\begin{array}{l}\text { Analyze a healthcare IS- related problem, identify and define the computing and } \\
\text { information systems requirements appropriate to its solution }\end{array}$ & $\mathrm{X}$ & $\mathrm{X}$ & $\mathrm{X}$ & $\mathrm{X}$ & & & \\
\hline $\begin{array}{l}\text { Design, implement, and evaluate a computer-based system, process, component, or } \\
\text { program to meet desired needs. }\end{array}$ & & & $\mathrm{X}$ & $\mathrm{X}$ & $\mathrm{X}$ & $\mathrm{X}$ & \\
\hline Function effectively in teams to create a project plan to accomplish a common goal. & & & & & & $\mathrm{X}$ & $\mathrm{X}$ \\
\hline Understand professional, ethical and social responsibilities. & & $\mathrm{X}$ & & & $\mathrm{X}$ & $\mathrm{X}$ & \\
\hline Communicate effectively with a range of audiences. & & & & $\mathrm{X}$ & & $\mathrm{X}$ & $\mathrm{X}$ \\
\hline $\begin{array}{l}\text { Analyze the impact of computing on individuals, organizations and society, including } \\
\text { ethical, legal, security and global policy issues }\end{array}$ & & $\mathrm{X}$ & & & $\mathrm{X}$ & $\mathrm{X}$ & \\
\hline $\begin{array}{l}\text { Apply current techniques, skills, and tools to enhance the operational and managerial } \\
\text { aspects of healthcare organizations }\end{array}$ & & & $\mathrm{X}$ & & & & \\
\hline $\begin{array}{l}\text { Understand the organizational, administrative, managerial, and regulatory processes that } \\
\text { support the delivery and management of evolving health systems }\end{array}$ & $\mathrm{X}$ & & $\mathrm{X}$ & & & & \\
\hline
\end{tabular}

These healthcare concentration objectives and outcomes map directly to the CIS program objectives and outcomes and are thus aligned with the university mission of preparing high caliber graduates of lifelong learning and serving the educational and professional needs of all stakeholders.

\section{PHASE C: DESIGNING COURSES}

\section{Establishing Technical And Professional Requirements Of The Curriculum}

Phase III of the curriculum design begins once the concentration outcomes and objectives are in place. In this phase, specific concentration specialization courses are designed based on certain criteria.

Literature review shows that a comprehensive curriculum should not equip graduates of the program with knowledge alone but proficiency in technical and non-technical skills are equally important (Karoly \& Panis, 2004; Smith, Hunt, berry \& Hunt, 2005; Calhoun, Vincent, Calhoun \& Brandsen, 2008). Addressing the local employment needs should not be the only objective for the BSc. HCIS-Concentration. Students from IS program should be able to accept jobs in widely dispersed geographic areas. Therefore, it is necessary to maintain programs that are consistent both with regional and national level employment job market and with the common body of knowledge of the IS field (IS, 2002). 
Rosenthal (2010) specifies a need to raise the level of content of IS curriculums so that the graduates are able to specify, estimate, evaluate, design, and implement high quality and successful systems, and continue to reduce the industry's project failure rate.

As stated by Alma and Nancy, "future careers will require higher levels of education than in the past. Education must enable individuals to discover what they need to know rather than just having static knowledge. Society will need college graduates with mental agility and adaptability" (Pedersen and O'Neill, 2005). They ask for an effective and coherent integration of technology into an enriched curriculum that meets both student and societal expectations.

ABET requires that programs seeking their accreditations must meet the nine criteria. A part of the fifth criteria, related to the curriculum:

Criterion 5: The program's requirements must be consistent with its program educational objectives and designed in such a way that each of the student outcomes can be attained. The curriculum must combine technical and professional requirements with general education requirements and electives to prepare students for a professional career and further study in the computing discipline associated with the program, and for functioning in modern society. The technical and professional requirements must include at least one year of up-to-date coverage of fundamental and advanced topics in the computing discipline associated with the program. In addition, the program must include mathematics appropriate to the discipline beyond the pre-calculus level. For each course in the major required of all students, its content, expected performance criteria, and place in the overall program of study must be published. (ABET)

ABET program criteria for Information Systems program specifically require that the curriculum should be designed so that:

Students have course work or an equivalent educational experience that includes:

a. Information Systems: One year that includes:

1. coverage of the fundamentals of a modern programming language, data management, networking and data communications, systems analysis and design and the role of Information Systems in organizations.

2. Advanced coursework that builds on the fundamental coursework to provide depth.

b. Information Systems Environment: One-half year of coursework that includes varied topics that provide background in an environment in which the information systems will be applied professionally.

c. Quantitative analysis or methods including statistics. (ABET)

\section{Accreditation Requirements Incorporated At CIT}

BSc. CIS degree consists of 41 courses, an internship, and an applied research project. Each course is worth three credits. Students must complete 129 credit hours to be awarded a BSc. degree. CIT requires the same 129 credit hours for the degree of BSc. with concentration in HCIS as shown in Table 2. However, the curriculum for BSC-CIS with concentration in HCIS has been customized to include 15 credit hours for HCIS concentration requirements comprising of five courses.

Table 2: Components Of HCIS Concentration Program (Credit Hours)

\begin{tabular}{|c|l|c|c|c|c|c|}
\hline S. No & \multicolumn{1}{|c|}{ Area } & $\mathbf{1}^{\text {st }}$ Year & $\mathbf{2}^{\text {nd }}$ Year & $\mathbf{3}^{\text {rd }}$ Year & $\mathbf{4}^{\text {th }}$ Year & Total \\
\hline 1 & General Education & 24 & 3 & & & 27 \\
\hline 2 & Humanities and Social Sciences & & 3 & & 3 & 6 \\
\hline 3 & Natural \& Applied Sciences & 3 & & & 3 & 6 \\
\hline 4 & Supporting IT & 3 & 9 & 12 & 3 & 27 \\
\hline 5 & Core IT Requirements & 3 & 21 & 12 & 12 & 48 \\
\hline 6 & HCIS Concentration Requirements & & & 3 & 12 & 15 \\
\hline & Total & $\mathbf{3 3}$ & $\mathbf{3 6}$ & $\mathbf{3 0}$ & $\mathbf{3 0}$ & $\mathbf{1 2 9}$ \\
\hline
\end{tabular}


IT courses in the HCIS curriculum are grouped as "IT Core requirements" and "Concentration Requirements". Table 3 shows the IT Core Requirement courses in the curriculum.

Table 3: IT Core Requirements

\begin{tabular}{|l|l|l|l|}
\hline \multicolumn{3}{|c|}{ IT Core Requirements } \\
\hline \multicolumn{1}{|c|}{ Course Code } & \multicolumn{1}{|c|}{ Course title Course Code } & \multicolumn{1}{c|}{ Course title } \\
\hline ITGN 220 & Software Project Management & ITGN 321 & Object-Oriented Analysis \& Design \\
\hline ITGN 230 & Introduction to Programming & ITGN 345 & Information Systems Security \\
\hline ITGN 235 & Principles of Networking & ITIS 414 & Strategic Issues in Information Systems \\
\hline ITGN 240 & Data Structures \& Algorithms & IT IS 405 & Internship (Summer or Winter) \\
\hline ITGN 245 & Operating Systems Administration & IT IS 440 & Capstone Project \\
\hline ITGN 250 & Database Management Systems & ITGN 350 & Web Design \& Development \\
\hline
\end{tabular}

\section{Introducing Concentration Requirement Courses}

Relevant and suitable HCIS concentration-specific courses and their learning outcomes have been designed carefully based on following criteria:-

Criteria 1. The requirement of equipping students with the HCIS knowledge \& skills areas that can be categorized as

- IT essentials

- Methodological and application-oriented

- Capturing the administrative and managerial aspects of the health care profession

Criteria 2. The coherence among the concentration courses and the trimming down of potential overlaps.

Criteria 3. ABET requirement of courses that builds on the fundamental courses to provide depth and courses that provide background in an environment in which the information systems will be applied professionally.

Criteria 4. The need to minimize the similarities among the various courses belonging to different concentrations, by exploring ways to share common courses across multiple concentrations.

Based on the design criteria given above, five specialization courses (given in Table 4 below) are introduced in HCIS concentration.

Table 4: HCIS Specialization Requirements.

\begin{tabular}{|l|l|l|}
\hline \multicolumn{2}{|c|}{ Course title } & \multicolumn{1}{c|}{ Course pre-requisite } \\
\hline \multicolumn{1}{|c|}{ Course Code } & \multicolumn{1}{|c|}{ Concentration Requirements (15 Cr. Hrs) } \\
\hline ITHS 450 & Healthcare Information Systems Management & ITGN 215: Introduction to Information Systems \\
\hline ITHS 451 & Healthcare Computer-based risk & ITGN 315: Object-Oriented Programming \\
\hline ITHS 453 & Healthcare Process Improvements & $\begin{array}{l}\text { ITGN 220: Software Project Management } \\
\text { BBUS 200: Quantitative Methods for Business }\end{array}$ \\
\hline ITHS 464 & Electronic /Mobile - Healthcare Systems & ITGN 350: Web Design \& Development \\
\hline ITIS 465 & Database Security and Audit & $\begin{array}{l}\text { ITGN 250: Database Management Systems } \\
\text { ITGN 345: Information Systems Security }\end{array}$ \\
\hline
\end{tabular}

The pre-requisite chart and the recommended sequence of courses is shown in the Figure 2. 


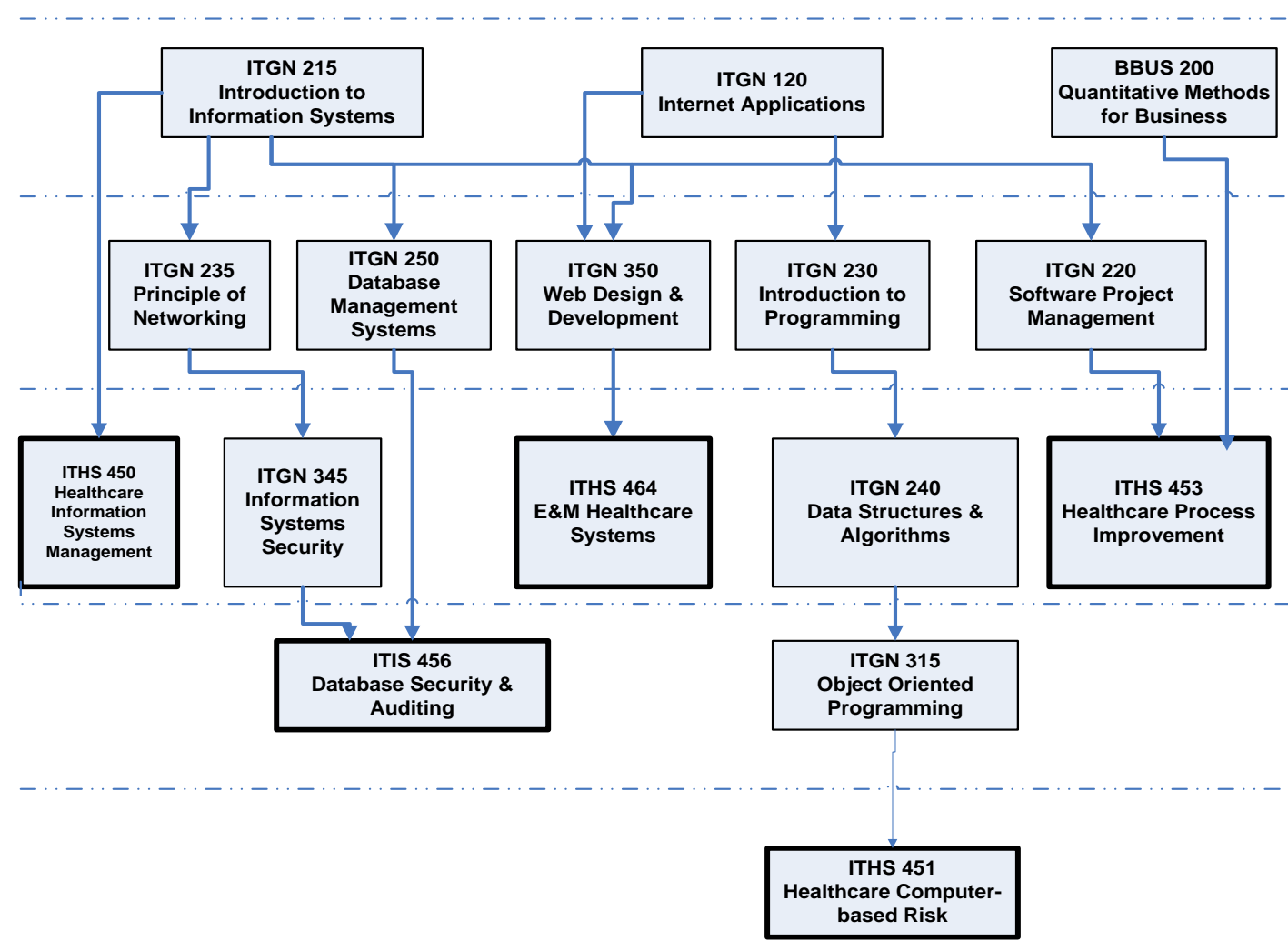

Figure 2: Sequences of IT Courses.

\section{Course Design Philosophy}

Criteria were used in designing the courses as below:

\section{- $\quad$ ITHS 450: Healthcare Information Systems Management}

In alignment with (criteria 1), this course will provide the necessary principles to prepare students to be managers by providing the knowledge, skills, and competencies necessary to manage healthcare information systems effectively. This knowledge will also allow students to become more involved in implementation of major healthcare IT initiatives.

A student with a basic understanding of information systems concepts will be able to take-up this course. Therefore, the course "Introduction to Information Systems" has been chosen as the pre-requisite to this course; in accordance to criteria 3.

\section{- $\quad$ ITHS 451: Healthcare Computer-based Risk}

This course provides an overview of the theory and applications of risk management practices within healthcare organizations and aims to develop students' ability to manage risk associated with potential system failures. It explains what needs to be done to achieve quality and compliance of computer systems in the pharmaceutical and healthcare industries successfully. This course will address criteria 1.

In this course, Java will be used as the implementation language to apply various risk management and validation techniques within healthcare applications. Hence, the course "object-oriented programming" has been 
selected as the pre-requisite course (criteria 3). This will enable students to have more hands-on experience in building computer systems thus preparing them to become knowledgeable participants not only in the HCIS planning, but in the implementation process, as well. (criteria 1).

- $\quad$ ITHS 453: Healthcare Process Improvements

This course exposes students to the programs, techniques, and tools for process improvements in healthcare settings. Students will learn quality and performance improvement tools and techniques and apply them to improve various healthcare processes like patient flow, patient scheduling, inventory tracking, management etc. This course will address the concepts and applications of IT knowledge area in HCIS (criteria 1). With the push towards decentralizing the IT decision-making process, it is imperative that healthcare administrators become adept at managing IT projects. Students will be gaining this knowledge/skill through the pre-requisite courses ITGN 220 Software project management, as well as the complementing courses: ITHS 453 - Healthcare process improvement and the ITHS 451 - Healthcare Computer-based Risk courses; thus complying with criteria 3.

- $\quad$ BBUS 200-Quantitative Methods for Business

Quantitative Methods for Business has also been selected as the pre-requisite for this course, as it equips students with the required background in Linear programming and decision analysis; thus complying with criteria 2.

- $\quad$ ITHS 464: Electronic / Mobile Healthcare Systems

This course emphasizes the web-enabled technologies, on-line health management, medical extranets, ecommerce and e-building plans, and emerging application of mobile and wireless networks in healthcare. This course will address the IT fundamental knowledge area of HCIS, measuring the Internet development technology skill/knowledge (criteria 1). As part of the course work, students will work on a project to develop an on-line health application. Hence, ITGN 350 - Web Design \& Development has been selected as the pre-requisite to this course (criteria 3)

- $\quad$ ITIS 465: Database Security and Audit

Security has always been a problem when implementing medical information systems, where data represent in many cases a valuable and sensitive asset. The fundamentals of database technology have been adequately addressed in ITGN 250 - Database Management Systems course. Hence, security of the database is the priority and the focus of this course. This course originally belongs to (and is shared with) the Information Systems Security concentration (criteria 4).

\section{Curriculum Mapping To Program Outcomes}

Finally mapping the program outcomes to the program curricula assist in the assessment of performance on each Program Outcome. This also helps in the detection of possible deficiencies and needs for improvement in the program.

A matrix which maps each HCIS concentration specialization course with the corresponding program level outcomes can be seen in Table 5 .

Table 5: Mapping CIS-HCIS Specialization Courses To Program Outcomes

\begin{tabular}{|c|c|c|c|c|c|c|c|c|c|c|c|}
\hline \multirow{2}{*}{\multicolumn{3}{|c|}{ Specialization Requirements (15 Cr. Hrs.) }} & \multicolumn{9}{|c|}{ Program Outcomes (PO) } \\
\hline & & & 1 & 2 & 3 & 4 & 5 & 6 & 7 & 8 & 9 \\
\hline 1 & ITHS 450 & Healthcare Information Systems Management & & & & & & & $\mathrm{X}$ & & $\mathrm{X}$ \\
\hline 2 & ITHS 451 & Healthcare Computer-based Risk & & $\mathrm{X}$ & $\mathrm{X}$ & & $\mathrm{X}$ & & $\mathrm{X}$ & $\mathrm{X}$ & $\mathrm{X}$ \\
\hline 3 & ITHS 453 & Healthcare Process Improvements & $\mathrm{X}$ & $\mathrm{X}$ & $\mathrm{X}$ & & & & & $\mathrm{X}$ & \\
\hline 4 & ITHS 464 & E/M-Healthcare Systems & & $\mathrm{X}$ & & & & & $\mathrm{X}$ & $\mathrm{X}$ & $\mathrm{X}$ \\
\hline 5 & ITIS 456 & Database Security \& Auditing & & $\mathrm{X}$ & & $\mathrm{X}$ & & & & $\mathrm{X}$ & $\mathrm{X}$ \\
\hline
\end{tabular}




\section{CONCLUSION}

College of Information Technology (CIT) offers a Bachelor of Science in Computing and Information Systems (CIS) degree. In response to the diversified market requirements in the region, and a need to maintaining the competitive edge, CIT redesigned its CIS program to have the program offered with several concentrations. Concentrations proposed to be added were concentration in Health Care Information Systems plus concentrations in Enterprise Information Systems, Information Systems Security, Electronic \& Mobile commerce, Network Administration \& Support, and Database Systems. Proposal was accepted by regulatory authorities.

Curriculum for the Health Care Information Systems concentration is developed to be in alignment with the university's mission. Consistent with its mission, the overall objective of the curriculum is to enable students to possess the intellectual foundation of knowledge, skills, values, and attitudes necessary to obtain entry-level positions in their chosen fields of expertise, and to contribute effectively to an ever-changing information systems environment.

While redesigning program, CIT had to face challenging issues, both internal and external like writing new proposals, motivating faculty members, budgeting, getting approvals, faculty recruitment plans, and deployment of resources. These issues lie outside the scope of this paper and hence are not discussed.

A rollout plan to introduce these concentrations over a period of three years was prepared. Currently CIT is offering a Bachelor of Science in CIS degree with three concentrations: Enterprise Information Systems, Information Systems Security, and Electronic \& Mobile Commerce. According to the rollout plan, HCIS is planned to be offered during 2011-12 academic year.

Curriculum development model presented in this paper ensures the quality standards of the curriculum by adopting the program accreditation criteria of ABET. It is recommended to use this model in designing undergraduate IT concentrations.

\section{RECOMMENDATIONS}

Besides following the ABET criteria for designing the curriculum, CIT solicited inputs from the various stakeholders including the faculty, Academic Advisory Council, Business Advisory Council, alumni, and currently enrolled CIT students. A market feasibility study was organized at the level of stakeholders. There were two surveys undertaken; first internal survey among students and faculty and second external survey among potential employers and alumni. As per the first survey results, the need for this concentration was felt mostly by the faculty. The second survey carried out among the healthcare organizations strongly recommended the need for graduates with specialization in healthcare information systems. These surveys were incomplete, as they did not gather information about the knowledge and skill areas that the prospective employers are looking for. Hence, these surveys have not been included in this paper. Well-designed surveys, conducted on large audiences are recommended to perceive the graduates skills and knowledge, more desired by the employers in the region.

\section{AUTHOR INFORMATION}

Shafaq Naheed Khan is working as a Lecturer at the University of Dubai. She has also been working as a Coordinator for several courses at the College of Information Technology. She holds a Master's degree in Computing and Information Systems from University of Hull, UK. She is active in research and has published several papers. Her research interests are in the field of e-commerce and Information Systems. She is currently member of professional societies such as Association for Information Systems. E-mail: skhan@ud.ac.ae

\section{REFERENCES}

1. ABET. Criteria for Accrediting Computing Programs, 2010-2011 Review Cycle (PDF). Retrieved from http://abet.org. 
2. Bewer, Horriger, \& Medonca (2006). Beyond the model: Building an effective and dynamic IT curriculum. Journal of Information Technology Education, Vol. 5, p441-458.

3. Calhoun, J. G., Vincent, E. T., Calhoun, G. L., \& Brandsen, L. E.. (2008). Why Competencies in Graduate health management and Policy Education?, The Journal of Health Administration Education, 17 -36.

4. Dodson, T. M. \& Giorcelli, R. J. (2008). Curriculum Decisions: Assessing and Updating IS Curriculum. Proceedings of the Fourteenth Americas Conference on Information Systems, Toronto, ON, Canada August 14th-17th 2008.

5. Grant Thornton's International Business Report on Healthcare (2010). Retrieved April 28, 2011 from http://www.gtuae.net/whats_new.html.

6. Gulf News (2008). Strong growth in UAE healthcare sector. Retrieved April 18, 2008 from http://www.uaeinteract.com/docs/Strong_growth in_UAE healthcare sector/33371.htm.

7. Hunt, S. (2004). Forward. In organizational \& end user information systems: Curriculum model for undergraduate education in information technology. Morehead, KY: Organizational Systems Research Association.

8. IS 2002: Model Curriculum and Guidelines for Undergraduate Degree Programs in Information Systems. Retrieved from http://www.acm.org/education/is2002.pdf.

9. Karoly,L.A. \& Panis,C.W.A. (2004). The 21st centuary at work:Forces shaping the future workforce and workplace in the United States, Santa Monica, CA: The RAND Corporation.

10. Landry, Daigle, Longenecker, \& Pardue (2010). IS 2002 and ABET Accreditation: Meeting the ABET Program Outcome Criteria. Information Systems Education Journal, 8 (67). http://isedj.org/8/67l. ISSN: 1545-679X.

11. Lang, Richard D. (2003). Healthcare Information Management Systems Concentration Curriculum Choices: Evaluating the CIO Perspective., Journal of Information Systems Education, Vol. 14(4) 373 380.

12. Lenox, Woratschek, \& Davis (2008). Exploring Declining CS/IS/IT Enrollments. Information Systems Education Journal, 6 (44). http://isedj.org/6/44/. ISSN:1545-679X. (Preliminary version appears in The Proceedings of ISECON 2005: §3124. ISSN:1542-7382.)

13. Mourshed, M., Hediger, V., \& Lambert, T.,(2006). Gulf Cooperation Council- Health Care: Challenges and Opportunities. Global Competitiveness Reports, Chapter 2.1. Retrieved March 20,2011 from https://members.weforum.org/pdf/Global_Competitiveness_Reports/Reports/chapters/2 1.pdf

14. Newzglobe.com (2011). Healthcare sector on hiring spree in UAE. Published on 2011-04-03. Retrieved from http://www.newzglobe.com.

15. Noll, Cheryl L. \& Wilkins, M. (2002). Critical Skills of IS professioanls: A Model for Curriculum Development. Journal of Information Technology Education, 143 -154.

16. Pedersen, Alma C., \& O’Neill, Nancy (2005). Curricula Designed to Meet 21st-Century Expectations from Educating the Net Generation, An EDUCAUSE E-book. Retrieved April 24, 2011 from http://net.educause.edu/ir/library/pdf/pub7101i.pdf.

17. Pharmaceutical Market Research. (2011). UAE Healthcare Sector Forecast to 2012. Published on April 2011. Retrieved from http://www.pharmaceutical-market-research.com.

18. Rosenthal (2010). Information Systems Education: What's missing? Information Systems Education Journal, 8 (37). http://isedj.org/8/37/. ISSN: 1545-679X. (A preliminary version appears in The Proceedings of ISECON 2009: §3323. ISSN: 1542-7382.)

19. Singh, S. K. (2011). Doctors Feel Good Now As Hiring Picks Up In UAE. Published on March 18, 2011. Retrieved from http://www.emirates247.com/news/emirates/doctors-feel-good-now-as-hiring-picks-up-inuae-2011-03-18-1.369829.

20. Smith, L. B., Hunt, C. S., Berry, R. \& Hunt. D. (2005). An Integrated IT curriculum model for advancing education in information technologies, learning and performance, Information Technology, Learning \& Performance Journal; Vol. 23 Issue 1, p7-19, 13p.

21. Thompson, Tommy. G., \& Brailer, David. J. (2004). The Decade of Health Information Technology:Delivering Consumer-centric and Information-rich Health Care, report published by the Office for the National Coordinator for Health Information Technology (ONCHIT), Department of Health and Human Services, and the United States Federal Government. 